Florida International University

FIU Digital Commons

FCE LTER Journal Articles

FCE LTER

2-3-2015

\title{
Factors affecting individual foraging specialization and temporal diet stability across the range of a large "generalist" apex predator
}

Adam E. Rosenblatt

Department of Biological Sciences, Marine Sciences Program, Florida International University, arosenbl@fiu.edu

James C. Nifong

Unviersity of Florida

Michael R. Heithaus

Department of Biological Sciences and Marine Sciences Program, Florida International University, heithaus@fiu.edu

Frank J. Mazzotti

University of Florida

Michael S. Cherkiss

U.S. Geological Survey

See next page for additional authors

Follow this and additional works at: https://digitalcommons.fiu.edu/fce_lter_journal_articles

Part of the Life Sciences Commons, and the Physical Sciences and Mathematics Commons

\section{Recommended Citation}

Rosenblatt, A.E., Nifong, J.C., Heithaus, M.R. et al. Oecologia (2015) 178: 5. doi:10.1007/s00442-014-3201-6

This material is based upon work supported by the National Science Foundation through the Florida Coastal Everglades Long-Term Ecological Research program under Cooperative Agreements \#DBI-0620409 and \#DEB-9910514. Any opinions, findings, conclusions, or recommendations expressed in the material are those of the author(s) and do not necessarily reflect the views of the National Science Foundation.

This work is brought to you for free and open access by the FCE LTER at FIU Digital Commons. It has been accepted for inclusion in FCE LTER Journal Articles by an authorized administrator of FIU Digital Commons. For more information, please contact dcc@fiu.edu, jkrefft@fiu.edu. 


\section{Authors}

Adam E. Rosenblatt, James C. Nifong, Michael R. Heithaus, Frank J. Mazzotti, Michael S. Cherkiss, Brian M. Jeffery, Ruth M. Elsey, Rachel A. Decker, Brian R. Silliman, Louis J. Guillette Jr., Russell H. Lowers, and Justin C. Larson 
1 Factors affecting individual foraging specialization and temporal diet stability across the

2 range of a large "generalist" apex predator

3

4 Adam E. Rosenblatt ${ }^{1, *}$, James C. Nifong ${ }^{2}$, Michael R. Heithaus ${ }^{1,3}$, Frank J. Mazzotti ${ }^{4}$, Michael S.

5 Cherkiss $^{5}$, Brian M. Jeffery ${ }^{4}$, Ruth M. Elsey ${ }^{6}$, Rachel A. Decker ${ }^{1}$, Brian R. Silliman ${ }^{2}$, Louis J.

6 Guillette Jr. ${ }^{7}$, Russell H. Lowers ${ }^{8}$, Justin C. Larson ${ }^{2}$

$8 \quad \underline{\text { Affiliations }}$

$9{ }^{1}$ Department of Biological Sciences, Marine Sciences Program, Florida International University, North Miami, FL 33181, USA

$11 \quad{ }^{2}$ University of Florida, Department of Biology, Gainesville, FL 32611, USA

$12{ }^{3}$ School of Environment, Arts, and Society, Florida International University, North Miami, FL 33181, USA

$14{ }^{4}$ Fort Lauderdale Research and Education Center, University of Florida, Davie, FL 33314, USA

15 U.S. Geological Survey, Southeast Ecological Science Center, Davie, FL 33314, USA

$16{ }^{6}$ Louisiana Department of Wildlife and Fisheries, Rockefeller Wildlife Refuge, Grand Chenier, LA 70643, USA

${ }^{7}$ Medical University of South Carolina, Department of Obstetrics and Gynecology and Hollings Marine Laboratory, Charleston, SC 29412, USA

$20 \quad{ }^{8}$ InoMedic Health Applications, Kennedy Space Center, FL 32899, USA

$21 \quad *$ Corresponding author: email: arose007@fiu.edu, phone: 215-913-4078, fax: 305-919-4030 ${ }^{1}$

\footnotetext{
${ }^{1}$ Author Contributions: AER, JCN, MRH, and FJM conceived the idea for the study. AER, JCN, MSC, BMJ, RME, RAD, LJG, RHL, and JCL collected the data. AER and RAD analyzed the data. AER, JCN, MRH, and BRS wrote the manuscript; all other authors provided editorial advice.
} 


\section{Abstract}

Individual niche specialization (INS) is increasingly recognized as an important

24 component of ecological and evolutionary dynamics. However, most studies that have

25 investigated INS have focused on the effects of niche width and inter- and intraspecific competition on INS in small-bodied species for short time periods, with less attention paid to

27 INS in large-bodied reptilian predators and the effects of available prey types on INS. We investigated the prevalence, causes, and consequences of INS in foraging behaviors across different populations of American alligators (Alligator mississippiensis), the dominant aquatic apex predator across the southeast US, using stomach contents and stable isotopes. Gut contents

31 revealed that over the short-term, although alligator populations occupied wide ranges of the INS

32 spectrum, general patterns were apparent. Alligator populations inhabiting lakes exhibited lower

33 INS than coastal populations, likely driven by variation in habitat type and available prey types.

34 Stable isotopes revealed that over longer time spans alligators exhibited remarkably consistent 35 use of variable mixtures of carbon pools (e.g., marine and freshwater food webs). We conclude 36 that INS in large-bodied reptilian predator populations is likely affected by variation in available 37 prey types and habitat heterogeneity, and that INS should be incorporated into management 38 strategies to efficiently meet intended goals. Also, ecological models, which typically do not 39 consider behavioral variability, should include INS to increase model realism and applicability. 40

$41 \quad$ Key words: American alligator, Alligator mississippiensis, stomach content analysis, stable 42 isotope analysis, food web 


\section{Introduction}

Intrapopulation foraging specialization can be attributed to differences between sexes

45 ("ecological sexual dimorphism"; Temeles et al. 2000), morphological types ("resource

46 polymorphisms"; Skulason and Smith 1995), and age groups (“ontogenetic niche shifts"; Polis

47 1984). Increasingly, however, it is recognized that individuals within a population can exhibit

48 considerable variation in trophic interactions that are not attributed to these factors, but instead to

49 individual niche specialization (INS) that may be caused by differences in learning,

50 morphological and physiological adaptive plasticity, and genetic and epigenetic expression (Dall

51 et al. 2012). Individual niche specialization has important potential implications for evolutionary

52 processes (Knudsen et al. 2010) and community and population dynamics (Bolnick et al. 2003;

53 Dall et al. 2012). For example, some sea otter (Enhydra lutris) populations consist of individuals

54 that exhibit extreme dietary specializations, possibly for their entire lives, likely resulting in low

55 intraspecific competition and variable responses of individuals to food web perturbations (Estes

56 et al. 2003).

A number of studies have examined various factors that affect the magnitude or

58 occurrence of INS, including niche size (Bolnick et al. 2007; Woo et al. 2008; Araujo et al. 2009;

59 Darimont et al. 2009), intraspecific competition (Estes et al. 2003; Tinker et al. 2008), and

60 interspecific competition (Bolnick et al. 2010). However, another variable, prey community

61 composition, has not been thoroughly examined as a potential factor affecting INS. Prey

62 community composition is important to consider in the context of INS because for some species

63 consumption of different prey types involves different handling times and attack success rates

64 (Holling 1959; Kislalioglu and Gibson 1976). For example, if a predator population's habitat

65 contains abundant easy-capture prey (e.g., gastropods), then individuals in the population could 
all consume large numbers of that prey group because of short handling times and high attack

67 success rates. Such foraging behavior would cause each individual to exhibit dietary patterns very similar to conspecifics, resulting in low INS. In contrast, a habitat containing few easycapture prey and different types of hard-capture prey (e.g., mammals and birds) could result in higher INS because the predators are less likely to all focus on the same elusive prey group and

71 experience similar attack success rates (e.g., Baird et al. 1992). Killer whales (Orcinus orca) in 72 the eastern North Pacific Ocean may fit such a pattern: two distinct groups of killer whales feed 73 on different prey types, with "transients" primarily consuming pinnipeds and "residents" 74 primarily consuming fish (Baird et al. 1992). For killer whales, pinnipeds are more difficult to 75 capture and require more handling time than fish (Baird et al. 1992), and the resulting dietary 76 specialization patterns of the two populations are highly divergent: residents display low dietary 77 variability with prey killed by residents dominated by one genus of fish (Oncorhynchus) which 78 makes up $98 \%$ of the diet, while transients display higher dietary variability with prey killed by 79 transients distributed over 10 genera with harbor seals (Phoca vitulina) making up 55\% of the diet (Ford et al. 1998).

81 The effects of prey community composition on INS are particularly important to 82 investigate for large apex predators because they generally roam widely and can inhabit multiple 83 ecosystems with different types of prey communities. Furthermore, large apex predator 84 populations are generally declining globally (Ripple et al. 2014) and understanding INS patterns 85 could be important for crafting appropriate conservation strategies (Bolnick et al. 2003). Some 86 studies have documented the presence of INS in apex predators (Baird et al. 1992; Estes et al. 87 2003; Tinker et al. 2008; Darimont et al. 2009; Matich et al. 2011; Thiemann et al. 2011), but 88 few have addressed INS in one species across habitats with different prey community 
89 compositions over large spatial scales. If there is variation in the strength of INS among different 90 populations of the same top predator species across space and time (e.g., Baird et al. 1992), then

91 the effects of those top predators on lower trophic levels could vary considerably within and 92 among populations and their roles may differ markedly across ecosystems. Here we investigate the prevalence and stability of INS as well as the effects of prey 94 community composition on INS in a well-studied large apex predator: the American alligator 95 (Alligator mississippiensis). Using complementary techniques, stomach contents analysis (SCA; 96 provides short-term dietary data) and stable isotope analysis (SIA; provides long-term dietary 97 data), we assess INS in alligators across their range and a variety of habitats. Alligators are excellent model "generalist" apex predators for such a study because: 1) their diets have been 99 examined across their range repeatedly, 2) they inhabit every type of fresh and brackish water 100 habitat across the southeastern US (Mazzotti and Brandt 1994), and 3) their diets at the 101 population level are typically highly diverse. We hypothesized that alligator populations 102 inhabiting lakes would display relatively low degrees of INS because of low habitat variability 103 and prey communities containing many easy-capture prey (Darby et al. 2006). Conversely, we 104 hypothesized that alligator populations in coastal habitats that have access to a variety of distinct 105 habitat types (e.g., freshwater marshes, dynamic estuarine zones, marine areas) and to fewer 106 easy-capture prey would exhibit higher degrees of INS. 
Stomach contents collection and analyses

We compiled alligator stomach contents data from seven published studies containing data collected from 1220 alligators between 1977 and 2004 and five new datasets collected from 232 alligators between 2007 and 2012 (Table 1). The datasets included samples from a wide

112 geographic range and many habitat types (freshwater lakes, mangrove rivers, salt marshes, 113 barrier islands; Fig. 1). In some studies stomachs were sampled as part of state control programs 114 (e.g., state-sanctioned hunting and nuisance alligator removal programs), while in others data 115 were collected non-lethally using the hose-Heimlich technique (Table 1; Fitzgerald 1989). In studies that examined the technique's efficacy, $100 \%$ of ingested prey items were recovered from

$11791 \%$ of the alligators tested (Fitzgerald 1989; Rice et al. 2005; Nifong et al. 2012); therefore, we assumed no sampling bias between studies that used lethal or non-lethal methods. Prey items

119 found in the stomach contents were classified to the lowest possible taxon either immediately 120 after collection or after preservation.

To assess the prevalence of INS in alligator populations we applied Roughgarden's

$122(1972,1979)$ concept of total niche width (TNW; full range of food resources used by a

123 population), which is subdivided into a between-individual component (BIC; variance in food

124 resource use between individuals) and within-individual component (WIC; variance in food 125 resource use within individuals), such that $\mathrm{TNW}=\mathrm{BIC}+\mathrm{WIC}$. If $\mathrm{BIC}>\mathrm{WIC}$ for a given 126 population, then the diets of individuals are more diverse in comparison to each other than they 127 are diverse within each individual. We divided BIC by TNW to generate an index of 128 specialization that varied between 0 and 1 , where $0=$ pure generalist population (individuals 129 completely overlap with population's resource use) and $1=$ pure specialist population 
130 (individuals do not overlap at all with other individuals in the population). We chose to focus on 131 the BIC/TNW index because it is simple to calculate and because other INS metrics generally

132 produce similar results (Bolnick et al. 2002). Calculations of BIC/TNW are biased by the 133 inclusion of individuals that only contain prey items from one prey group in their stomach 134 (Bolnick et al. 2002), so we applied sorting rules to each dataset to limit bias in our INS results 135 and produce more conservative BIC/TNW values (explanation in electronic supplemental 136 materials). Individual specialization metrics like BIC/TNW are difficult to compare across 138 populations without accounting for variable numbers of available prey types across different 139 habitats. Thus, to standardize our BIC/TNW values we converted them into adjusted $E$ values 140 (Eadj; Araujo et al. 2011) using the equation

$141 \quad E_{\text {adj }}=\frac{E_{\text {obs }}-E_{\text {null }}}{E_{\text {max }}-E_{\text {null }}}$

142 where $E_{\text {obs }}$ is the observed BIC/TNW value, $E_{\text {null }}$ is the average BIC/TNW value generated by a 143 Monte Carlo resampling procedure which assumes each individual samples randomly from a 144 shared resource pool (explanation in electronic supplemental materials), and $E_{\max }$ is the 145 maximum possible BIC/TNW value for a given population. The variable $E_{\max }$ can be calculated 146 using the equation $1-1 / P$, where $P$ is the number of prey categories (families; see electronic 147 supplemental materials) consumed by a predator population.

148 Since diet variation can be caused by sexual and ontogenetic differences, as well as 149 inherent temporal and spatial prey variability, we needed to control for these potentially 150 confounding factors before we could quantify INS. Therefore, we tested each stomach contents 151 dataset to see if the datasets varied as a function of the variables capture season, capture year, 152 capture location, size, and sex (Table S1) using principal component analysis and multivariate 
153 analysis of variance (MANOVA; Araujo et al. 2007; explanation in electronic supplemental

154 materials). If MANOVAs revealed that any of the independent variables were significant

155 predictors of stomach contents variation in any given dataset, we divided the dataset into smaller

156 subsets to remove the bias (e.g., splitting the dataset into male and female subsets to control for

157 sex differences in diets). We chose the subsets of each dataset with sample sizes of at least 10

158 individuals for BIC/TNW analysis using the program IndSpec 1.0 (Bolnick et al. 2002), then

159 converted the BIC/TNW values into $E_{a d j}$ values. We used the program's Monte Carlo procedure

160 to test the null hypothesis that any observed variation in diet was caused by individuals sampling

161 randomly from a shared resource pool (Araujo et al. 2007; explanation in electronic

162 supplemental materials).

163

164 Stable isotope collection and analyses

165 For the purposes of INS analyses, SIA can be very useful because different tissues within 166 the same consumer can incorporate isotopes from the diet over different time periods (i.e.,

167 "turnover rates"; Dalerum and Angerbjorn 2005). Thus, multiple tissues collected from one 168 individual can provide insight into the relative stability of dietary patterns - or at least basal 169 carbon sources consumed - over multiple timescales. Although identifying specific consumed 170 prey taxa with SIA is difficult for generalist carnivores with broad diets, SIA is still useful 171 because values of $\delta^{13} \mathrm{C}$ are indicative of the origin of a consumer's nutrients (Fry 2006).

172 Tissue-specific turnover rates can vary widely between species (Dalerum and Angerbjorn 173 2005). A diet-switch study of juvenile alligators (Rosenblatt and Heithaus 2013) revealed that the 174 approximate complete turnover time of alligator plasma for $\delta^{13} \mathrm{C}$ (252 days) was roughly half 175 that of red blood cells (RBCs; 566 days). Therefore, if $\delta^{13} \mathrm{C}$ values for an alligator were similar 
across these tissue types it would suggest that the mixture of carbon pools used across an eight month period prior to sample collection is similar to that used across a 19-month period prior to sample collection. Differing $\delta^{13} \mathrm{C}$ values would indicate shifts in the relative contributions of different carbon pools across these timescales. For our analyses we used stable isotope data from plasma and RBC samples from 214 alligators collected between 2008 and 2012 from six sites

(Table 1; see Rosenblatt and Heithaus (2013) for sample collection procedures and the electronic supplemental materials for laboratory analysis procedures).

Before assessing the prevalence of INS in the alligator populations using SIA we needed to remove the possibility that our results were affected by variable fractionation factors between the two tissues (Dalerum and Angerbjorn 2005). Therefore, we subtracted experimentally determined fractionation values (isotopic differences between tissues and diet) for each alligator tissue $\left(+0.35 \%\right.$ or plasma $\delta^{15} \mathrm{~N},-0.04 \%$ or for plasma $\delta^{13} \mathrm{C},+0.95 \%$ or for $\operatorname{RBC} \delta^{15} \mathrm{~N}$, and $+0.03 \%$ o for RBC $\delta^{13} \mathrm{C}$; Rosenblatt and Heithaus 2013) from the $\delta$ values for each tissue. Then, MANOVAs were used to determine if the stable isotope datasets were significantly affected by the variables capture season, capture location, size, or sex. We only focused on the $\delta^{13} \mathrm{C}$ values of the two tissues as the dependent variables because they contain information about nutrient origins. After controlling for possible confounding variables and the potential effects of fractionation factors, we determined correlation coefficients for each dataset to see if the relationships between the $\delta^{13} \mathrm{C}$ values of plasma and RBCs were linear and positive (i.e., exhibited correlation coefficients close to one). We then employed linear regression to further examine the relationship between the $\delta^{13} \mathrm{C}$ values of plasma and RBCs. If individual alligators exhibited stable foraging patterns over the long time periods represented by the two tissues, we would expect the $\delta^{13} \mathrm{C}$ values of plasma and RBCs to be highly correlated, with linear regression 
199 best-fit lines characterized by high $\mathrm{R}^{2}$ values and slopes close to one. Conversely, if alligators

200 exhibited more variable foraging patterns we would expect best-fit lines characterized by low $\mathrm{R}^{2}$

201 values and slopes farther away from one. All statistical analyses were performed in SPSS 17.0

202 (IBM, Armonk, NY, USA) and SigmaPlot 11.0 (Systat, Chicago, IL). 


\section{Results}

Stomach contents

The alligators in this study consumed a diverse array of prey. The number of prey

206 families consumed per study ranged from 11 to 38 (mean $=23.1 \pm 9.2$ SD) and the mean number

207 of individual prey items consumed per alligator per study ranged from 4.5 to 34.8 (mean $=16.5 \pm$ 208 11.3 SD). Prey included crustaceans, mollusks, fishes, amphibians, reptiles, mammals, birds, 209 aquatic and terrestrial insects, and seeds (Table S2). Alligators with empty stomachs made up $6.1 \%(\mathrm{~N}=89)$ of all the individuals (mean per study $=7.3 \% \pm 6.7 \mathrm{SD})$, and $27.8 \%(\mathrm{~N}=403)$ of 211 alligator stomachs contained only 1 prey item or 2 prey items in the same prey category (mean 212 per study $=26.3 \% \pm 14.5 \mathrm{SD}$ ). Therefore, according to our sorting rules, we removed $33.9 \%$ of 213 the alligators from further analyses, leaving 960 individuals. The PCA-MANOVA analyses revealed that for most of the datasets (7 out of 12 total)

215 there existed differences in diet separate from INS (Table S1). Capture location was a significant 216 predictor of dietary patterns in 60\% (3 of 5) of lake studies and 67\% (2 of 3) of estuarine 217 habitats. Capture season was a significant predictor of dietary patterns in all three of the studies 218 in which it was included and capture year was a significant predictor in two (67\%) of the studies. 219 Alligator size was a significant predictor of dietary patterns in 58\% of the studies (7 of 12) 220 whereas sex was a significant predictor in two of the nine (22\%) studies in which it was 221 included.

After subdividing each dataset to control for significant predictor variables, the resulting 223 Shark River dataset was removed from further analyses because it was heavily skewed by two 224 individuals that each consumed thousands of anchovies (Engraulidae). The remaining 28 225 populations and sub-populations only included 23 monophagous individuals between them and 
226 produced $E_{a d j}$ specialization values that varied widely, with a minimum of 0.03 and a maximum

227 of $0.74($ mean $=0.39 \pm 0.19 \mathrm{SD}$; Table 2$)$. The Monte Carlo simulations revealed that despite the 228 wide range of observed BIC/TNW values, all but one population exhibited significantly greater 229 specialization than predicted by chance (Table 2). The $E_{a d j}$ values were not affected by sample 230 size (linear regression: $\mathrm{R}^{2}=0.007, P=0.7$ ), but the $E_{a d j}$ values were significantly different 231 between habitat types ( $\mathrm{t}$-test: $\mathrm{t}_{26}=-2.7, P=0.01$ ), with populations from lakes exhibiting lower 232 values $($ mean $=0.35 \pm 0.17 \mathrm{SD})$ than populations from coastal habitats (mean $=0.58 \pm 0.14 \mathrm{SD}$ ). Mollusks were one of the most frequently consumed prey groups across the populations 234 and there was a significant negative relationship between the $E_{\text {adj }}$ values of a population and the 235 number of mollusks consumed as a percentage of the population's total diet $\left(\mathrm{R}^{2}=0.3, P=0.003\right.$; 236 Fig. 2). There were also striking differences in mollusk consumption between lake and coastal 237 populations: lake populations consumed significantly more mollusks per individual $($ mean $=9.0$ $238 \pm 12.0 \mathrm{SD}$ ) than coastal populations (mean $=0.2 \pm 0.1 \mathrm{SD} ;$ Mann-Whitney $\mathrm{U}$ test: $\mathrm{U}=1, P<$ 239 0.001) and significantly more mollusks as a percentage of the population's total diet $($ mean $=$ $51.0 \% \pm 26.0 \mathrm{SD}$ ) than coastal populations (mean $=1.5 \% \pm 2 \mathrm{SD} ; \mathrm{U}=1, P<0.001)$. Lastly, our analyses indicated lake alligator populations used fewer potential prey categories present in their

242 habitat $(48 \% \pm 21 \mathrm{SD})$ when compared to coastal populations (70\% $\pm 35 \mathrm{SD})$, though this

243 difference was not statistically significant (Mann-Whitney $\mathrm{U}$ test: $\mathrm{U}=37, P=0.2$ ).

Stable isotopes

The fractionation-corrected $\delta^{13} \mathrm{C}$ values from both plasma and RBCs varied in the stable 247 isotope datasets with five of the six populations exhibiting wide $\delta^{13} \mathrm{C}$ ranges (Table 3 ). We did 248 not use the Lake Woodruff isotopes in our analyses because the $\delta^{13} \mathrm{C}$ ranges for both plasma and 
249 RBCs (Table 3) were too small to confidently estimate INS in this population. The large $\delta^{13} \mathrm{C}$ 250 ranges in the other alligator populations are indicative of the large ranges in $\delta^{13} \mathrm{C}$ values of 251 resource pools available to the alligator populations in each habitat (Peterson and Howarth 1987;

252 Gu et al. 1997; Rosenblatt and Heithaus 2011; Adams and Paperno 2012) and that individuals 253 within these populations display considerable variation in the proportions of food they consume 254 from these different resource pools over the timescales of plasma and RBC turnover. Capture location (freshwater/intermediate/marine habitats) was a significant predictor of $256 \delta^{13} \mathrm{C}$ values in two of the three estuarine studies (Table S1). Also, sex had a significant effect on $257 \quad \delta^{13} \mathrm{C}$ values in the Lake Apopka study so only males were included in analyses (Table S1). In 258 addition, size had a significant effect on $\delta^{13} \mathrm{C}$ values in the Sapelo Island study (Table S1), with 259 the two smaller alligator size classes displaying much lower $\delta^{13} \mathrm{C}$ values than the two larger size 260 classes. For eight out of nine subpopulations from the five isotope datasets plasma and $\mathrm{RBC} \delta^{13} \mathrm{C}$ 261 values exhibited tight linear relationships, with correlation coefficient (Pearson's $r$ ) values 262 ranging from 0.88 to 0.99 (mean $=0.96 \pm 0.04 \mathrm{SD})$. The Guana River population was the lone 263 outlier with a Pearson's $r$ value of 0.52 . The results of linear regression also showed that the $\delta^{13} \mathrm{C}$ 264 values of the two tissues were highly correlated, with $\mathrm{R}^{2}$ values ranging from 0.77 to 0.99 (mean $265=0.92 \pm 0.07 \mathrm{SD}$, all $P<0.001)$ and with slopes very close to 1 , ranging from 0.79 to 1.08 266 (mean $=0.96 \pm 0.09 \mathrm{SD} ;$ Fig. 3). Indeed, seven of the eight slope values did not differ 267 significantly from a slope of 1 (all $P>0.1$ ). The lone outlier again was the Guana River 268 population, which also showed a positive relationship but a lower $\mathrm{R}^{2}$ value $(0.28)$ and slope 269 (0.49). 


\section{Discussion}

Our results show that species thought to be dietary generalists and that exhibit broad

272 population level diets can actually specialize at the individual level. Stomach contents analysis

273 revealed that alligator populations exhibit different short-term dietary patterns, ranging from

274 generalized to more specialized populations. We also found the strength of short-term INS was

275 context dependent, with populations from lakes containing many easy-capture prey exhibiting

276 lower INS than populations from other habitats containing fewer easy-capture prey. In addition,

277 SIA revealed long-term stability in the use of different carbon pools by individual alligators

278 despite large differences between the $\delta^{13} \mathrm{C}$ values of those carbon pools: eight out of nine

279 populations we studied from both lake and coastal habitats contained individuals with

280 remarkably consistent $\delta^{13} \mathrm{C}$ values over moderate to long time spans, indicating that alligators

281 generally maintain the same foraging patterns through time regardless of habitat type.

282 Importantly, INS existed in addition to the dietary variation caused by differences between sexes, 283 life stages, seasons, years, and locations.

Consistent with our hypotheses, our findings suggest that one of the main drivers of INS, 285 at least in the short-term, is habitat heterogeneity and prey community composition. Lower $E_{a d j}$ 286 values in alligator populations inhabiting lakes could be a consequence of low habitat variation 287 in lakes and their well-defined boundaries. For example, Lake Apopka in central Florida, whose 288 alligator population was sampled several times across our datasets, has been a shallow, 289 homogenous, turbid, algal-dominated lake lacking a diverse fishery since 1947 (Bachmann et al. 290 1999). In contrast, the estuarine habitats sampled across our datasets contain a diversity of 291 aquatic habitats (freshwater, estuarine, marine) and have diffuse boundaries, thus potentially 292 allowing for greater movement of alligators and greater ingress of possible prey taxa. In fact, 
movement studies indicate that alligators inhabiting lakes move shorter distances and occupy smaller ranges than alligators in coastal habitats, and lake alligators largely restrict themselves to littoral areas (Goodwin and Marion 1979; Rosenblatt et al. 2013). Together, these observations suggest that lake-bound alligators have access to less distinct habitat types and prey groups than coastal populations. Consistent with this hypothesis, our analyses indicated lake alligator populations used fewer prey categories present in their habitat when compared to non-lake populations, though this result was not statistically significant.

Though the specific effects of habitat heterogeneity on INS have not been examined extensively, our findings agree with the few studies that have been done. For example, in a study of wolf (Canis lupus) feeding patterns in coastal British Columbia researchers found that wolves inhabiting island habitats exhibited relatively more among-individual dietary variation than mainland wolves. This difference was at least partially attributable to the fact that island wolves had access to multiple food webs (terrestrial and marine) embedded in a spatially heterogenous area while mainland wolves only used one food web (terrestrial) in a more spatially homogenous area (Darimont et al. 2009). Furthermore, trophic niche width of a population, a factor that can affect INS, also can decrease as habitat heterogeneity decreases (Layman et al. 2007). These studies broadly agree with our results, but more research on the effects of habitat heterogeneity on INS across a greater diversity of species and habitats is needed to confirm our findings. Our results further suggest that prey community composition can drive short-term INS because the $E_{a d j}$ values were negatively correlated with the number of mollusks consumed by a population as a percentage of the whole diet. We hypothesize that the presence of abundant easycapture prey like mollusks in certain habitats may allow the majority of alligators in those habitats to take frequent advantage of a resource so easily found and consumed. However, when 
mollusks are not as abundant alligators must pursue more mobile prey that are harder to capture.

317 These contrasting contexts would make each individual's short-term diet in mollusk-rich habitats

318 (i.e., lakes; Darby et al. 2006) more similar to conspecifics, thereby decreasing INS, but more

319 different from conspecifics in habitats containing less abundant mollusks, thereby increasing INS

320 (e.g., Baird et al. 1992; Tinker et al. 2008). In the latter context dietary variation between

321 individuals could be caused by resource patchiness rather than behavioral specialization, but

322 available evidence suggests that alligators do not move randomly through their environment

323 because individuals visit the same foraging areas over multiple years (Rosenblatt and Heithaus

324 2011; Rosenblatt et al. 2013). Although individuals may return to similar locations for periods of

325 time, their foraging trips take them to areas with prey supported by different carbon sources (e.g.

326 marine versus freshwater production). Thus, INS in habitats dominated by more mobile prey

327 could be caused by fine-scale associations between individual alligators and specific areas or by

328 individuals learning to eat different prey.

329 The effects of prey capture difficulty on INS have not been extensively studied, but our

330 results agree with those from killer whales which show that as prey capture difficulty increases

331 INS increases as well (Baird et al. 1992; Ford et al. 1998). However, a more recent study on

332 much smaller predators (wasps; Crabronidae and Sphecidae) showed the opposite effect of prey

333 capture difficulty on INS (Polidori et al. 2013). These incongruent results may be the result of

334 different habitat types (aquatic vs. terrestrial), differences in prey modes of movement (flying vs.

335 swimming), or differences in scale. Regardless of the cause of the differences it is clear that the

336 effects of prey capture difficulty can affect INS and more research is needed to identify the

337 mechanisms involved. 
Stomach contents analysis has specific drawbacks pertaining to INS. For example, SCA can be biased by variable digestive rates of different prey items. Prey with indigestible parts

340 (e.g., arthropods with chitinous exoskeletons, turtles, mollusks) may become over-represented in 341 the diet because they remain in the stomach longer than soft-bodied vertebrate prey (Garnett 342 1985; Janes and Gutzke 2002; Nifong et al. 2012). This factor can cause some prey to appear 343 more frequently and in higher numbers in stomachs, which may bias dietary analyses. However, 344 most of the prey groups consumed by alligators in our synthesis have at least one indigestible 345 part (e.g., mammal hair, bird feathers, crustacean exoskeletons, snail shells) which means 346 variable digestive rates likely did not have a large effect on our results, with the exception of a 347 possible underestimation of amphibians and fishes (Table S2).

There are three additional caveats associated with our stomach contents analyses. First, 349 we are confident that alligators exhibit non-random foraging behaviors, thereby violating one of 350 the assumptions of the Monte Carlo null hypothesis testing procedure. This means that the 351 statistical significance of our INS results is not conservative and should be viewed with caution. 352 Second, intraspecific competition is known to affect INS (Estes et al. 2003; Tinker et al. 2008) 353 and to account for this factor we would need to include alligator density and prey density in our 354 analyses. Unfortunately, both of these forms of data were not available for any of the locations 355 we included in our analyses, so there is a possibility that our INS results were also affected by 356 differences in intraspecific competition between habitat types. Third, we grouped alligator prey 357 by family because we assumed that alligators do not discriminate between prey on the species or 358 even genus level. If alligators do actually show preferences on the species or genus level, then 359 our INS estimates would be conservative and real alligator INS values may be higher, i.e. 360 alligator populations may be more specialized. In contrast, if the opposite were true and 
361 alligators do not discriminate between prey even on the family level, then alligator populations 362 may actually be less specialized.

SIA revealed that alligators generally exhibited highly consistent use of different carbon

364 pools across longer time frames. The consistent $\delta^{13} \mathrm{C}$ values we observed across tissues could

365 have been caused by specialization on specific prey but could also be attributed to consistent use

366 of specific habitats and movement patterns. We hypothesize that the latter explanation is more

367 likely, i.e. that alligators specialize in certain behavioral patterns, like specific foraging and

368 movement tactics. This possibility was partially accounted for in our study by separating

369 analyses for individuals captured in different habitats, but because of their high mobility

370 alligators captured in the same habitat still could move across the landscape in different ways.

371 Our hypothesis is supported by a previous study of alligator movement patterns in the Shark

372 River where alligators exhibited temporally stable variation in movement patterns (Rosenblatt

373 and Heithaus 2011; Rosenblatt et al. 2013): half of the alligators regularly commuted between

374 freshwater/estuarine and marine habitats and the stable isotope values of their skin indicated that

375 they were consistently feeding in two different food webs, whereas other alligators limited their

376 movements and feeding strictly to freshwater/estuarine habitats. Similar patterns appear to occur

377 in sea turtles, although on a different time scale, in that individual turtles will use consistent

378 "corridors" to move between nesting and foraging areas and will return to the same foraging

379 areas repeatedly, or individuals from the same nesting populations may be either coastal or

380 pelagic in their foraging habitats (see Heithaus 2013 for a review). Our study and others point to

381 the difficulties in using SIA to infer INS behaviors as a standalone data source when turnover

382 rates of even "fast" tissues are long, as in most reptiles (Rosenblatt and Heithaus 2013), because

383 in such situations SIA fails to capture short-term dietary choices. Therefore, we echo previous 
384 studies in suggesting that INS studies should combine isotope data with other behavioral data

385 where possible. We should also note that the turnover rate of alligator plasma is almost $50 \%$ of

386 the turnover rate for alligator RBCs, thus inherently biasing our analyses towards strong

387 correlations between the $\delta^{13} \mathrm{C}$ values of the two tissues. However, despite this methodological

388 artifact we are confident in our results because of the remarkable strength of the correlations

389 across almost every alligator population we sampled.

390

Many current ecosystem management and conservation strategies assume that all apex

391 predators in a population will have similar effects on prey populations. However, if behaviors

392 vary consistently across individuals, as our study and those of other taxa (Bolnick et al. 2003)

393 suggest, then one-size-fits-all conservation and management strategies may have unintended

394 consequences in many systems. For example, the Shark River is part of the Everglades which is

395 an ecosystem currently undergoing large-scale restoration (Doren et al. 2009). Restoration

396 activities are expected to bring more freshwater to the area, thereby decreasing salinity and

397 potentially increasing habitat quality for alligators that are dependent on freshwater (Mazzotti

398 and Brandt 1994). Since many of the alligators in this system appear to specialize in exploiting

399 the marine food web seasonally (Rosenblatt and Heithaus 2011), increased freshwater flow may

400 positively impact this group by allowing them to access marine resources for a larger portion of

401 each year (though the distribution of marine prey may change as well). However, individuals that

402 do not currently take advantage of marine resources may not experience the same future benefits.

403 In addition, the spatial scale of alligator movements, and therefore potential coupling of food

404 webs and nutrient transport (Rosenblatt and Heithaus 2011), likely will change. As freshwater

405 moves seaward, any individuals exploiting marine food webs will not need to move as far

406 upstream for osmoregulation. Similarly, in northern Kenya, African wild dog (Lycaon pictus) 
populations outside of protected areas exhibit specialized feeding on smaller prey than populations inside protected areas (Woodroffe et al. 2007). Thus, if wild dog conservation efforts were solely aimed at bolstering large prey populations some wild dogs may see no benefit unless their feeding patterns are very plastic. Different restoration and conservation scenarios, therefore, may differentially benefit subsets of apex predator populations. As a result, restoration and conservation actions may not achieve their intended goals if individual behavioral specialization is not explicitly considered during the planning process.

Our results also have important implications for food web theory and ecosystem models. Theoretical analyses have shown that top predators that couple different food webs through their foraging and movement behaviors contribute both local and non-local stability to the food webs (Rooney et al. 2006), but such models treat individuals in predator populations as behaviorally homogenous. By incorporating behaviorally heterogenous predator populations into food web and ecosystem models, realism of theoretical analyses and scenarios will increase (Quevedo et al. 2009). These next-generation models may reveal insights into the potentially nuanced roles of top predators in ecosystems and allow for the development of additional testable hypotheses. Ultimately, our research shows that INS in large apex predators can vary substantially among populations and the degree of inter-individual variation is likely affected by habitat type and prey community composition. Future research could make valuable contributions to our understanding of INS by investigating the relative effects of prey community composition, niche width, and inter- and intraspecific competition across a wider range of taxonomic groups, body sizes, and trophic levels. In the context of INS in large apex predators, it remains to be seen how subpopulations exhibiting different behaviors will respond to specific ecosystem conservation and management scenarios, but it is clear that INS needs to be explicitly considered in such plans 
430 as well as in food web models. 
443 Permit No. SPGS-10-44R and SPGS-10-43, Georgia Department of Natural Resources Scientific

444 Collecting Permit No. 29-WBH-10-33, and Everglades National Park Permit No. 0024, 0025,

445 and 0031. We thank all the volunteers who assisted with field work and data collection,

446 especially Phil Matich, Kirk Gastrich, Katy Cameron, Greg Mineau, and Derek Burkholder. Use

447 of trade, product, or firm names does not imply endorsement by the U.S. Government or the

448 authors. All work carried out in this study comply with the current laws of the USA. We declare

449 that we have no conflict of interest. 


\section{References}

Adams D, Paperno R (2012) Stable isotopes and mercury in a model estuarine fish: multibasin comparisons with water quality, community structure, and available prey base. Sci Total Env $414: 445-455$

Araujo M, Bolnick DI, Machado G, Giaretta AA, dos Reis SF (2007) Using $\delta^{13} C$ stable isotopes to quantify individual-level diet variation. Oecologia 152:643-654

Araujo M, Bolnick DI, Martinelli LA, Giaretta AA, dos Reis SF (2009) Individual-level diet variation in four species of Brazilian frogs. J Anim Ecol 78:848-856

Araujo M, Bolnick DI, Layman CA (2011) The ecological causes of individual specialisation. Ecol Lett $14: 948-958$

Bachmann R, Hoyer MV, Canfield DE (1999) The restoration of Lake Apopka in relation to alternative stable states. Hydrobiologia 394:219-232

Bolnick D, Yang LH, Fordyce JA, Davis JM, Svanback R (2002) Measuring individual-level resource specialization. Ecology 83:2936-2941

Bolnick D, Svanback R, Fordyce JA, Yang LH, Davis JM, Husley CD, Forister ML (2003) The ecology of individuals: incidence and implications of individual specialization. Am Nat 161:1-28

Bolnick D, Svanback R, Araujo MS, Persson L (2007) Comparative support for the niche variation hypothesis that more generalized populations also are more heterogeneous. Proc Natl Acad Sci 104:10075-10079

Bolnick D, Ingram T, Stutz WE, Snowberg LK, Lau OL, Paull JS (2010) Ecological release from interspecific competition leads to decoupled changes in population and individual niche width. Proc R Soc B 277:1789-1797

Dalerum F, Angerbjorn A (2005) Resolving temporal variation in vertebrate diets using naturally occurring stable isotopes. Oecologia 144:647-658 
474 Dall S, Bell AM, Bolnick DI, Ratnieks FLW (2012) An evolutionary ecology of individual differences. Ecol $475 \quad$ Lett 15:1189-1198

476 Darby P, Bennetts RE, Karunaratne LB (2006) Apple snail densities in habitats used by foraging snail

477

478

479

480

481

482

483

484

485

486

487

488

489

490

491

492

493

494

495

496

497 kites. Fla Field Nat 34:37-47

Darimont C, Paquet PC, Reimchen TE (2009) Landscape heterogeneity and marine subsidy generate extensive intrapopulation niche diversity in a large terrestrial vertebrate. J Anim Ecol 78:126-133

Delany M, Abercrombie CL (1986) American alligator food-habits in north-central Florida. J Wildl Manag $50: 348-353$

Delany M, Woodward AR, Kochel IH (1988) Nuisance alligator food habits in Florida. Fla Field Nat 16:9096

Delany M (1990) Late summer diet of juvenile American alligators. J Herpetol 24:418-421

Delany M, Linda SB, Moore CT (1999) Diet and condition of American alligators in 4 Florida lakes. Proc Annu Conf Southeast Assoc Fish Wildl Agencies 53:375-389

Doren R, Trexler JC, Gottlieb AD, Harwell MC (2009) Ecological indicators for system-wide assessment of the greater Everglades ecosystem restoration program. Ecol Indic 9S:S2-S16

Elsey R, McNease L, Joanen T, Kinler N (1992) Food habits of native wild and farm-released juvenile alligators. Proc Annu Conf Southeast Assoc Fish Wildl Agencies 46:57-66

Estes J, Riedman ML, Staedler MM, Tinker MT, Lyon BE (2003) Individual variation in prey selection by sea otters: patterns, causes and implications. J Anim Ecol 72:144-155

Fitzgerald L (1989) An evaluation of stomach flushing techniques for crocodilians. J Herpetol 23:170-172

Ford J, Ellis GM, Barrett-Lennard LG, Morton AB, Palm RS, Balcomb KC (1998) Dietary specialization in two sympatric populations of killer whales (Orcinus orca) in coastal British Columbia and adjacent waters. Can J Zool 76:1456-1471

Fry B (2006) Stable isotope ecology. Springer, New York, NY 
501

Gabrey S (2010) Demographic and geographic variation in food habits of American alligators (Alligator mississippiensis) in Louisiana. Herpetol Conserv Biol 5:241-250

Garnett S (1985) The consequences of slow chitin digestion on crocodilian diet analyses. J Herpetol 19:303-304

Goodwin T, Marion WR (1979) Seasonal activity and habitat preferences of adult alligators in a northcentral Florida lake. J Herpetol 13:157-164

Gu B, Schelske CL, Hoyer MV (1997) Intrapopulation feeding diversity in blue tilapia: evidence from stable-isotope analyses. Ecology 78:2263-2266

Heithaus M (2013) Predators, prey, and the ecological roles of sea turtles. In: Wyneken J, Lohmann KJ, Musick JA (eds) The biology of sea turtles, vol III. CRC Press, Boca Raton, FL, pp 249-284

Holling C (1959) Some characteristics of simple types of predation and parasitism. Can Entomol 91:385398

Janes D, Gutzke WHN (2002) Factors affecting retention time of turtle scutes in stomachs of American alligators, Alligator mississippiensis. Am Midl Nat 148:115-119

Kislalioglu M, Gibson RN (1976) Prey "handling-time" and its importance in food selection by the 15spined stickleback, Spinachi spinachia (L.). J Exp Mar Biol Ecol 25:151-158

Knudsen R, Primicerio R, Amundsen P, Klemetsen A (2010) Temporal stability of individual feeding specialization may promote speciation. J Anim Ecol 79:161-168

Layman C, Quattrochi JP, Peyer CM, Allgeier JE (2007) Niche width collapse in a resilient top predator following ecosystem fragmentation. Ecol Lett 10:937-944

Matich P, Heithaus MR, Layman CA (2011) Contrasting patterns of individual specialization and trophic coupling in two marine apex predators. J Anim Ecol 80:294-305 
Mazzotti F, Brandt LA (1994) Ecology of the American alligator in a seasonally fluctuating environment. In: Davis D, Ogden J (eds) Everglades: the ecosystem and its restoration. St. Lucie Press, Delray Beach, FL, pp 485-505

Nifong J, Rosenblatt AE, Johnson NA, Barichivich W, Silliman BR, Heithaus MR (2012) American alligator digestion rate of blue crabs and its implications for stomach contents analysis. Copeia 2012:419423

Peterson B, Fry B (1987) Stable isotopes in ecosystem studies. Annu Rev Ecol Syst 18:293-320

Polidori C, Santoro D, Blüthgen N (2013) Does prey mobility affect niche width and individual specialization in hunting wasps? A network-based analysis. Oikos 122:385-394

Polis G (1984) Age structure component of niche width and intraspecific resource partitioning: can age groups function as ecological species? Am Nat 123:541-564

Quevedo M, Svanback R, Eklov P (2009) Intrapopulation niche partitioning in a generalist predator limits food web connectivity. Ecology 90:2263-2274

Rice A, Ross JP, Finger AG, Owen R (2005) Application and evaluation of a stomach flushing technique for alligators. Herpetol Rev 36:400-401

Rice A, Ross JP, Woodward AR, Carbonneau DA, Percival HF (2007) Alligator diet in relation to alligator mortality on Lake Griffin, FL. Southeast Nat 6:97-110

Ripple W, Estes JA, Beschta RL, Wilmers CC, Ritchie EG, Hebblewhite M, Berger J, Elmhagen B, Letnic M, Nelson MP, Schmitz OJ, Smith DW, Wallach AD, Wirsing AJ (2014) Status and ecological effects of the world's largest carnivores. Science 343:1241484

Rooney N, McCann K, Gellner G, Moore JC (2006) Structural asymmetry and the stability of diverse food webs. Nature 442:265-269

Rosenblatt A, Heithaus MR (2011) Does variation in movement tactics and trophic interactions among American alligators create habitat linkages? J Anim Ecol 80:786-798 
544 Rosenblatt A, Heithaus MR (2013) Slow isotope turnover rates and low discrimination values in the

$545 \quad$ American alligator: implications for interpretation of ectotherm stable isotope data. Physiol $546 \quad$ Biochem Zool 86:137-148

547 Rosenblatt A, Heithaus MR, Mazzotti FJ, Cherkiss M, Jeffery B (2013) Intra-population variation in 548 activity ranges, diel patterns, movement rates, and habitat use of American alligators in a 549 subtropical estuary. Estuar Coast Shelf Sci 135:182-190

550 Roughgarden J (1972) Evolution of niche width. Am Nat 106:683-718

551 Roughgarden J (1979) Theory of population genetics and evolutionary ecology: an introduction.

$552 \quad$ Macmillan, New York, NY

553 Skulason S, Smith TB (1995) Resource polymorphisms in vertebrates. Trends Ecol Evol 10:366-370

554 Temeles E, Pan IL, Brennan JL, Horwitt JN (2000) Evidence for ecological causation of sexual dimorphism

555 in a hummingbird. Science 289:441-443

556 Thiemann G, Iverson SJ, Stirling I, Obbard ME (2011) Individual patterns of prey selection and dietary specialization in an Arctic marine carnivore. Oikos 120:1469-1478

558 Tinker M, Bentall G, Estes JA (2008) Food limitation leads to behavioral diversification and dietary 559 specialization in sea otters. Proc Natl Acad Sci 105:560-565

560

Woo K, Elliott KH, Davidson M, Gaston AJ, Davoren GK (2008) Individual specialization in diet by a generalist marine predator reflects specialization in foraging behaviour. J Anim Ecol 77:1082-

562 1091

563 Woodroffe R, Lindsey PA, Romanach SS, Ranah SMKO (2007) African wild dogs (Lycaon pictus) can subsist on small prey: implications for conservation. J Mammal 88:181-193 
Table 1 Summary information for the American alligator stomach contents and stable isotope studies used in analyses.

\begin{tabular}{|c|c|c|c|c|c|}
\hline Data source & Locations & Habitat type & Duration & Collection method & $\mathbf{N}$ \\
\hline \multicolumn{6}{|c|}{ Stomach contents } \\
\hline $\begin{array}{l}\text { Delany and } \\
\text { Abercrombie } 1986\end{array}$ & $\begin{array}{l}\text { Orange, Lochloosa, \& Newnans } \\
\text { Lakes, FL }\end{array}$ & Lake & 1981-1983 & Hunter harvested alligators & 349 \\
\hline Delany et al. 1988 & $\begin{array}{l}\text { Duval, St. Johns, Alachua, Marion, } \\
\text { Citrus, \& Lake counties, FL }\end{array}$ & Lake & 1977 & Sacrificed nuisance alligators & 78 \\
\hline Delany 1990 & Orange Lake, FL & Lake & 1986 & Sacrificed alligators & 77 \\
\hline Elsey et al. 1992 & Marsh Island, LA & Island & 1991 & Hunter harvested alligators & 101 \\
\hline Delany et al. 1999 & $\begin{array}{l}\text { Rodman, George, Hancock, \& } \\
\text { Trafford Lakes, FL }\end{array}$ & Lake & 1985 & Hunter harvested alligators & 231 \\
\hline Rice et al. 2007 & $\begin{array}{l}\text { Apopka, Griffin, \& Woodruff Lakes, } \\
\text { FL }\end{array}$ & Lake & 2001-2003 & $\begin{array}{l}\text { Hose-Heimlich stomach } \\
\text { flushing }\end{array}$ & 172 \\
\hline Gabrey 2010 & $\begin{array}{l}\text { Lafourche, Terrebonne, Cameron, } \\
\text { Vermilion, \& St. Charles parishes, LA }\end{array}$ & Marsh & 2002-2004 & Hunter harvested alligators & 212 \\
\hline \multirow{4}{*}{ This study } & Apopka \& Woodruff Lakes, FL & Lake & 2010 & $\begin{array}{l}\text { Hose-Heimlich stomach } \\
\text { flushing and necropsies }\end{array}$ & 29 \\
\hline & Merritt Island, FL & Island & 2010 & $\begin{array}{l}\text { Hose-Heimlich stomach } \\
\text { flushing and necropsies }\end{array}$ & 10 \\
\hline & Shark River, FL & Estuary & 2009-2011 & $\begin{array}{l}\text { Hose-Heimlich stomach } \\
\text { flushing }\end{array}$ & 54 \\
\hline & Guana River, FL & Estuary & 2011-2012 & $\begin{array}{l}\text { Hose-Heimlich stomach } \\
\text { flushing }\end{array}$ & 40 \\
\hline $\begin{array}{l}\text { J. Nifong (unpub. } \\
\text { data) }\end{array}$ & Sapelo Island, GA & Island & 2007-2010 & $\begin{array}{l}\text { Hose-Heimlich stomach } \\
\text { flushing }\end{array}$ & 99 \\
\hline \multicolumn{6}{|c|}{ Stable isotopes } \\
\hline \multirow{4}{*}{ This study } & Apopka \& Woodruff Lakes, FL & Lake & 2010 & NA & 29 \\
\hline & Merritt Island, FL & Island & 2010 & NA & 10 \\
\hline & Shark River, FL & Estuary & 2008-2011 & NA & 79 \\
\hline & Guana River, FL & Estuary & 2011-2012 & NA & 40 \\
\hline $\begin{array}{l}\text { J. Nifong (unpub. } \\
\text { data) }\end{array}$ & Sapelo Island, GA & Island & 2009-2010 & NA & 56 \\
\hline
\end{tabular}


Table 2 Results of American alligator stomach contents specialization analyses. BIC/TNW = Between Individual Component/Total Niche Width alligators.

571

\begin{tabular}{|c|c|c|c|c|c|c|c|c|c|}
\hline Data source & Location & Sample date & Sex & Size (TL; cm) & $\mathbf{N}$ & $\begin{array}{c}\text { BIC/TNW } \\
\left(E_{\text {obs }}\right)\end{array}$ & $\begin{array}{c}\text { BIC/TNW MC } \\
\left(E_{\text {null }}\right)\end{array}$ & $\begin{array}{c}E_{\max } \text { (prey } \\
\text { categories) }\end{array}$ & Eadjusted \\
\hline \multirow{10}{*}{$\begin{array}{l}\text { Delany and } \\
\text { Abercrombie } 1986\end{array}$} & Orange Lake, FL & Fall 1983 & $\mathrm{M}, \mathrm{F}$ & $200-250$ & 22 & $0.71^{* *}$ & 0.20 & $0.94(17)$ & 0.69 \\
\hline & Lochloosa Lake, FL & Fall 1981 & $M, F$ & $150-200$ & 10 & $0.68 * *$ & 0.20 & $0.9(10)$ & 0.69 \\
\hline & Orange Lake, FL & Fall 1982 & $\mathrm{M}, \mathrm{F}$ & $150-200$ & 22 & $0.58 * *$ & 0.38 & $0.93(14)$ & 0.36 \\
\hline & Orange Lake, FL & Fall 1981 & $M, F$ & $250-300$ & 10 & $0.55^{* *}$ & 0.40 & $0.94(16)$ & 0.28 \\
\hline & Orange Lake, FL & Fall 1983 & $M, F$ & $100-150$ & 12 & $0.52^{* *}$ & 0.28 & $0.93(14)$ & 0.37 \\
\hline & Orange Lake, FL & Fall 1982 & $\mathrm{M}, \mathrm{F}$ & $200-250$ & 19 & $0.52^{* *}$ & 0.42 & $0.93(15)$ & 0.19 \\
\hline & Orange Lake, FL & Fall 1983 & $M, F$ & $250-300$ & 13 & $0.51^{* *}$ & 0.32 & $0.92(13)$ & 0.32 \\
\hline & Orange Lake, FL & Fall 1982 & $\mathrm{M}, \mathrm{F}$ & $250-300$ & 10 & $0.48 * *$ & 0.35 & $0.88(8)$ & 0.25 \\
\hline & Newnan's Lake, FL & Fall 1983 & $\mathrm{M}$ & $300-350$ & 15 & $0.48 * *$ & 0.32 & $0.91(11)$ & 0.27 \\
\hline & Newnan's Lake, FL & Fall 1983 & $\mathrm{M}, \mathrm{F}$ & $200-250$ & 11 & $0.43^{* *}$ & 0.22 & $0.9(10)$ & 0.31 \\
\hline Delany et al. 1988 & Griffin \& Tsala Apopka Lakes, FL & Summer 1977 & $\mathrm{M}, \mathrm{F}$ & $100-350$ & 27 & 0.58 & 0.57 & $0.93(14)$ & 0.03 \\
\hline \multirow[b]{2}{*}{ Delany 1990} & Orange Lake, FL & Fall 1986 & NA & $50-100$ & 27 & $0.56 * *$ & 0.25 & $0.91(11)$ & 0.47 \\
\hline & Orange Lake, FL & Fall 1986 & NA & $0-50$ & 27 & $0.54 * *$ & 0.24 & $0.9(10)$ & 0.45 \\
\hline Elsey et al. 1992 & Marsh Island, LA & Summer 1991 & $\mathrm{M}, \mathrm{F}$ & $100-200$ & 81 & $0.57^{* *}$ & 0.22 & $0.95(22)$ & 0.48 \\
\hline \multirow{6}{*}{ Delany et al. 1999} & Rodman Lake, FL & Summer 1985 & $\mathrm{M}$ & $250-300$ & 15 & $0.45^{* *}$ & 0.11 & $0.94(16)$ & 0.41 \\
\hline & George Lake, FL & Summer 1985 & $\mathrm{M}, \mathrm{F}$ & $150-200$ & 18 & $0.46 * *$ & 0.18 & $0.92(12)$ & 0.38 \\
\hline & George Lake, FL & Summer 1985 & $\mathrm{M}, \mathrm{F}$ & $100-150$ & 12 & $0.44 * *$ & 0.16 & $0.89(9)$ & 0.38 \\
\hline & Rodman Lake, FL & Summer 1985 & $\mathrm{M}, \mathrm{F}$ & $200-250$ & 11 & $0.33^{* *}$ & 0.08 & $0.89(9)$ & 0.31 \\
\hline & George Lake, FL & Summer 1985 & $\mathrm{M}, \mathrm{F}$ & $200-250$ & 10 & $0.55^{* *}$ & 0.44 & $0.89(9)$ & 0.25 \\
\hline & Rodman Lake, FL & Summer 1985 & $\mathrm{M}$ & $300-350$ & 10 & $0.24^{* *}$ & 0.14 & $0.91(11)$ & 0.13 \\
\hline Rice et al. 2007 & Woodruff Lake, FL & Fall 2002 & $\mathrm{M}, \mathrm{F}$ & $200-250$ & 12 & $0.70 * *$ & 0.10 & $0.92(12)$ & 0.73 \\
\hline Gabrey 2010 & Freshwater marsh, LA & Fall 2004 & $\mathrm{M}$ & 75-100 (SVL) & 15 & $0.79 * *$ & 0.57 & $0.9(10)$ & 0.67 \\
\hline \multirow{3}{*}{ This study } & Merritt Island, FL & Spring 2010 & M & $250-350$ & 7 & $0.69 * *$ & 0.07 & $0.91(11)$ & 0.74 \\
\hline & Guana River, FL & Summer 2011-2012 & $\mathrm{M}, \mathrm{F}$ & $50-250$ & 30 & $0.64 * *$ & 0.11 & $0.95(21)$ & 0.63 \\
\hline & Apopka \& Woodruff Lakes, FL & Spring 2010 & $\mathrm{M}, \mathrm{F}$ & $200-350$ & 20 & $0.47^{* *}$ & 0.35 & $0.92(13)$ & 0.21 \\
\hline J. Nifong (unpub. data) & Sapelo Island, GA & Spring 2008 & M & $50-100$ & 10 & $0.50 * *$ & 0.29 & $0.83(6)$ & 0.39 \\
\hline
\end{tabular}

$572 \quad * * P<0.001$ (Monte Carlo bootstraps, 500 simulations)

573 All others, $P=0.3$ 
574 Table 3 Summary of fractionation-corrected $\delta^{13} \mathrm{C}$ ranges for plasma and red blood cells (RBC) for each American alligator population used in the 575 study.

\begin{tabular}{|c|c|c|c|c|c|c|}
\hline Location & Min plasma $\delta^{13} \mathrm{C}(\% \circ)$ & Max plasma $\delta^{13} \mathrm{C}(\% \circ)$ & Plasma $\delta^{13} \mathrm{C}$ mean \pm SD (\%o) & Min RBC $\delta^{13} C(\%)$ & Max RBC $\delta^{13} \mathrm{C}(\% 0)$ & RBC $\delta^{13} \mathrm{C}$ mean \pm SD (\%o) \\
\hline Sapelo Island, GA & -29.4 & -15.3 & $-21.5 \pm 4.5$ & -28.0 & -14.0 & $-21.0 \pm 4.5$ \\
\hline Lake Apopka, FL & -25.9 & -11.9 & $-16.5 \pm 4.9$ & -25.2 & -12.1 & $-16.3 \pm 4.8$ \\
\hline Shark River, FL & -30.3 & -19.2 & $-26.2 \pm 2.1$ & -28.7 & -21.1 & $-26.0 \pm 1.7$ \\
\hline Guana River, FL & -24.6 & -18.0 & $-20.8 \pm 1.3$ & -25.0 & -18.0 & $-21.1 \pm 1.4$ \\
\hline Merritt Island, FL & -22.8 & -16.8 & $-19.0 \pm 2.0$ & -23.2 & -15.2 & $-18.0 \pm 2.3$ \\
\hline Lake Woodruff, FL & -26.4 & -24.4 & $-25.4 \pm 0.6$ & -26.0 & -23.3 & $-24.8 \pm 0.7$ \\
\hline
\end{tabular}

576 


\section{$578 \quad$ Figure captions}

Fig. 1 Map of alligator sampling locations used for diet specialization analyses. Circles = lakes, squares $=$ islands, triangles $=$ marshes, and diamonds $=$ rivers/estuaries. Black shapes represent

582 locations where only stomach contents were collected and gray shapes represent sites where both 583 stomach contents and tissues for stable isotope analysis were collected

Fig. 2 Specialization values $\left(E_{a d j}\right)$ of different American alligator populations as predicted by mollusk consumption (total number of mollusks consumed by population divided by total number of all prey items consumed by population). Black line is linear regression trend line

Fig. 3 Linear regression plots depicting relationships between alligator plasma $\delta^{13} \mathrm{C}$ values and red blood cell $\delta^{13} \mathrm{C}$ values. a Lake Apopka, FL (males, lake habitat, 250-400 cm total length

592 Island, GA (males, marine habitat, 50-100 cm TL), d Shark River, FL (males and females, 593 estuarine habitat, $150-300 \mathrm{~cm} \mathrm{TL})$. All $P<0.001$. Note different scales on axes 